\title{
On the syntactic nature of the Dutch prefix be-
}

\author{
Paula Fenger, Ava Creemers and Marlijn Meijer \\ University of Connecticut / University of Pennsylvania / Humboldt- \\ Universität zu Berlin
}

This paper provides a novel syntactic analysis of the Dutch prefix be-. This prefix can derive new verbs by attaching to verbs (be-vind $\mathrm{V}_{\mathrm{V}}$-en 'to be located'), nouns (be-dijk $\mathrm{N}_{\mathrm{N}}$-en 'to dam up') or adjectives (be-groot $\mathrm{A}_{\mathrm{A}}$-en 'to economize'). It can also form new adpositions by combining with adjectives (be-need $d_{\mathrm{A}}$-en, 'below') or prepositions (be-ove $(r)_{\mathrm{P}}$-(e)n 'above'). We propose an analysis of be- based on Aboh's (2010) account for complex locative expressions in typologically different languages, including Gungbe, Zina Kotoko, English and Dutch. We extend this analysis to Dutch verbal complexes, and argue that $b e$ - expresses a functional category $\left(\mathrm{F}^{\circ}\right)$ that embeds a predicate phrase containing the element it attaches to, in both adpositions and verbs. Our analysis goes against Hoekstra, Lansu and Westerduin's (1987) small clause account of be- in verbal complexes in which beis the head of a predicate phrase $\left(\operatorname{Pr}^{\circ}\right)$.

Keywords: Dutch prefixes, predication, syntax, morphology

\section{Introduction}

This paper focuses on the status of the Dutch prefix be-, which can form both verbs and adpositions. Be-attaches to various parts of speech such as verbs, nouns, adjectives, adverbs and prepositions, as in examples (1a-d), as well as to roots, as in (1e) (also see De Haas and Trommelen 1993). The category of the base is given between brackets.

(1)
Base
Verb
a. kijk 'look' (V)
be-kijk-en 'to watch'
b. $\quad$ dijk 'dike' $(\mathrm{N})$
be-dijk-en 'to provide with a dike'
c. zat 'drunken' (A)
be-zat $(\mathrm{t})$-en 'to hit the bottle'
d. $\sqrt{G I N}_{\text {(root) }}$ be-gin(n)-en 'to start'

1. All examples of verbs are followed by the infinitival suffix -en. 
The meaning of be-, when forming a verb, can be described as 'to direct an action towards an object such that the object is affected' (De Vries 1975). The entity, property, or action denoted by the base lexical elements $b e$ - attaches to, plays a role in that action (Booij 2002: 113). In terms of productivity, be- $\mathrm{N}$ and $b e-\mathrm{V}$ combinations are productive and $b e-\mathrm{A}$ combinations are not.

Additionally, the prefix be- in Dutch may also form adpositions, as illustrated in (2). We follow Aboh (2010) in assuming that adpositions such as buiten 'outside' are derived phrases. Aboh argues that such an adposition is a morphologically and structurally complex item in which be- selects a phrase embedding uit-en 'out-INFL'.

(2)
Base
a. ned(er) 'low' (Adv)
Adposition
b. ov(er) 'on' (P)
be-neden 'below'
c. zuid 'south' (A)
b-oven 'above'
d. zijde 'side' $(\mathrm{N})$
be-zuiden 'south of'
be-zijden 'alongside'

Adpositions formed with $b e$ - are not productive, whereas the verb forming be-is productive when it attaches to nouns and verbs. This paper focuses on the parallelism between the occurrence of the prefix $b e$-in verbs and in adpositions, which has not yet been investigated. ${ }^{1}$

We aim to provide a novel and uniform syntactic analysis of the occurrence of be-in verbs as well as in adpositions, on the basis of Aboh's (2010) account of complex locative constructions. We claim that the distribution of be-is best explained by assuming that it is a functional head $\left(\mathrm{F}^{\circ}\right)$ that embeds a predicate phrase (Section 2). This analysis captures all occurrences of be- (i.e. in adpositions and verbs). We further contrast our analysis to the analysis by Hoekstra, Lansu and Westerduin (1987), in which the prefix be- is assumed to head a predicate phrase $\left(\mathrm{Pr}^{\circ}\right)$ within a Small Clause. We show that this analysis runs into several problems that do not arise in our analysis (Section 3). In Section 4, we discuss some of the extensions of our approach and Section 5 concludes.

1. While this paper will only discuss the Dutch prefix be-, we do want to stress that similar constructions can be found in other Germanic languages, such as in English where one can find the same parallelism between verbs formed with be-(be-come, be-fringe) and prefixes formed with be- (be-low, be-side). Arguably, the analysis proposed here should extend to those cases as well. We return to these cases in future work. 


\section{Be-as a Functional Projection}

This section first describes Aboh's (2010) analysis for adpositions, and shows that complex adpositions involve the same underlying structure cross-linguistically (2.1). Building on Aboh's analysis we propose a novel account for be-derived verbs in Dutch (2.2).

\subsection{From Adpositions in Gungbe to Dutch (Aboh 2010)}

Based on cross-linguistic data, Aboh (2010) argues that adpositions such as English be-side or in-front-of are complex phrases. An example of such a complex phrase is given in (3), in which the first part of the complex phrase (in) relates the FIGURE (he) to the GROUND (the house), and the other part of the phrase (to) represents the part of the GROUND that serves to locate he (following Talmy 2000).

(3) He ran into the house.

As Aboh (2010:253) argues this would mean that in and to started out as two independent elements to+in though in subsequently raises to to in surface syntax. This view is compatible with data from Gungbe and Zina Kotoko. In both languages, adpositions are formed by the combination of two types of items derived from two distinct word classes and labeled as P1 (the RELATOR, such as in in (3)) and P2. Interestingly, P1 and P2 occur on both sides of the GROUND cross-linguistically, as shown in (4) and (5).

(4) Gungbe

Kj̀jó zé gò ló dó àkpótín ló mè

Kojo take bottle DET P1 box DET P2

'Kojo put the bottle inside the box' (Aboh 2010:225)

(5) Zina Kotoko

Kàrtà dé a gmá táblòl

cards DET P1 P2 table

'The cards are on the table' (Holmberg 2002: 163)

In Gungbe, (4), we see that inside is expressed by a P1 item dó, which precedes the DP-Ground, which in turn precedes a P2 item mì highlighting some part of ground. The complex adposition thus circumvents the DP-Ground àkpótín ló 'the box' and the resulting order is $\mathrm{P} 1>\mathrm{DP}>\mathrm{P} 2$. In Zina Kotoko, (5), on top of is expressed by a gmá, a P1 and a P2 item, which as a complex precedes the DPGROUND táblsl 'table', resulting in the order P1-P2-DP. Under this view, English to corresponds to P1 while in corresponds to P2. This description further suggests 
that English is just one stage further than Zina Kotoko as P2 seems to raise to adjoin to P1 yielding in-to. Aboh's (2010) crosslinguistic study further shows that P1 and P2 emerge from two word classes: verbs or relators, and landmark nouns, respectively.

As such, these items show different semantic and morphosyntactic properties. P1 items typically encode direction and may function as relators, introduce new arguments and assign case. P2 items, on the contrary, typically encode location but do not introduce new arguments and do not assign case. They generally occur inside a DP introduced by a verb or P1-like element (4-5). For a more extensive overview of the properties of P1 and P2 items and their independent syntactic behavior, the reader is referred to Aboh (2010). The relevant differences the reader should keep in mind are repeated and summarized in Table 1.

Table 1. P1 and P2 items in Gungbe and Zina Kotoko

\begin{tabular}{lll}
\hline Property & P1 items & P2 items \\
\hline source & verbs & nouns \\
code & source, direction, goal & location \\
\hline
\end{tabular}

Based on the syntactic behavior of the $\mathrm{P}$ items, Aboh proposes the structure in (6) for such complex adpositions. ${ }^{2}$

(6)

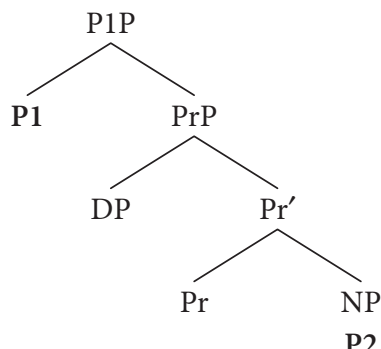

Aboh builds his analysis on Bowers' (1993) theory of the predicate phrase (PrP). The PrP hosts the external object in its specifier and takes a predicate, such as a VP

2. The reader should keep in mind that the structure in Aboh (2010) is in two ways more complex: (i) In between the P1P and PrP there is a FP where the inverted P2 element in Zina Kotoko can land; (ii) Aboh (2010) assumes that a small clause, PrP, consists of a defective clause which includes IP and CP. Therefore, P2 may include inflection. However, for ease of exposition, we will use P1P > PrP throughout the paper, since nothing in our analysis hinges on the presence or absence of these functional projections. 
or NP, as its complement. ${ }^{3}$ In the structure in (6), the P1 item is the head of a functional phrase above the PrP; the $\mathrm{P} 2$ item is the head of a predicative bare NP selected that functions as complement of $\mathrm{Pr}^{\circ}$. This creates the classical configuration for $\mathrm{N}$ to be incorporated into $\mathrm{Pr}^{\circ}$ (Baker 1988). In terms of the structure in (6), adpositions as in Gungbe can be represented as in (7); the DP àtín lo' 'the tree' is in SpecPrP, while the element ji ' top' expressing $\mathrm{P} 2$ incorporates into $\mathrm{Pr}^{\circ}$.

(7) $\left[_{\mathrm{P} 1 \mathrm{P}}\left[{ }_{\mathrm{P} 1}\right.\right.$ dó $\left[\mathrm{PrP}_{\mathrm{P}}\right.$ àtín ló $\left[_{\mathrm{Pr}_{\mathrm{o}}}\right.$ jí $\left[{ }_{\mathrm{NP}}\right.$ jíl] $\left.\left.]\right]\right]$

P1 tree DET P2

'on the tree top'

The structure in (6) can also explain the adpositions found in Zina Kotoko. The only difference in this language is that $\mathrm{P} 2$ incorporates into $\mathrm{Pr}^{\circ}$ and that the so-formed complex $\mathrm{P} 2-\mathrm{Pr}^{\circ}$ further raises to a higher position to the left of the GROUND, as shown in (8). ${ }^{4}$

$$
\begin{aligned}
& {\left[_{\mathrm{P} 1 \mathrm{P}}\left[{ }_{\mathrm{P} 1} \text { a gmá }\left[{ }_{\mathrm{PrP}} \text { táblòl }\left[{ }_{\mathrm{Pr}^{\circ}} \text { gmá }\left[{ }_{\mathrm{NP}} \text { gmá }\right]\right]\right]\right]\right]} \\
& \text { P1 P2-PR table }{ }_{\text {P2-PR }}
\end{aligned}
$$

'on the table'

As mentioned above, Aboh (2010) argues this analysis holds for English and Dutch complex adpositions as well. This is illustrated for Dutch buiten 'outside' in (9).

$$
\begin{aligned}
& {\left[{ }_{\mathrm{P} 1 \mathrm{P}}\left[{ }_{\mathrm{P} 1} \text { b } \mathrm{b} \text { uit-en }\left[{ }_{\mathrm{PrP}}\left[{ }_{\mathrm{DP}} \text { de cirkel }\right]\left[\left[_{\mathrm{Pr}} \text { out-en }\left[{ }_{\mathrm{NP}} \text { uit }\right]\right]\right]\right]\right]\right.} \\
& \text { P1-P2-PR the circle } \\
& \text { 'outside the circle' }
\end{aligned}
$$

Aboh assumes that buiten consists of $\mathrm{P} 1$ item be- and $\mathrm{P} 2$ item uit. The assumption is that be-is comparable to relators, while uit derives from a locative noun. In the $\mathrm{P} 1$ position we find be-above the PrP. The $\mathrm{P} 2$ position, being the complement of $\operatorname{PrP}$, hosts uit, which obtains infinitival inflection by incorporation into the $\operatorname{Pr}^{\circ}$. Next, uit moves up further to P1 item be-, forming a complex element, similar to the adpositions in Zina Kotoko. Note that the same can also be said of English adpositions as beside, which can be decomposed into be (P1) and side (P2).

To summarize, Aboh shows that spatial expressions in Gungbe, Zina Kotoko, Dutch and English are complex phrases involving the underlying structure in (6). A major prediction of this analysis is that one expects elements functioning as P1

3. The PrP has the potential to create a small clause when taking a NP or AP as a complement. Such a small clause can function as a separate discourse unit (see e.g. the small clause John crazy in They consider $\left[_{\mathrm{PrP}}\right.$ John $\left[_{\mathrm{AP}}\right.$ crazy $\left.\left.]\right]\right)$.

4. The movement of $\mathrm{P} 2$ is motivated independently by Aboh, on the basis of predicate (head) inversion data from Hausa and Gbe genitive constructions (Aboh 2010:39-47). 
to derive other phrases than locatives. We claim that this is the case in $b e-\mathrm{V}, b e-\mathrm{A}$, and $b e-\mathrm{N}$ combinations in Dutch, in which P1 selects for a nominal, verbal, or adjectival predicate.

\subsection{Our proposal}

We argue that the examples in (1) and (2) can be derived on the basis of the same structure as complex adpositions. Our claim is that be- realizes a functional projection (P1P) that embeds a predicate phrase, that can be headed by a verb, a noun or an adjective. In other words, we treat these elements synchronically as verbs, adpositions, nouns, adjectives, but their internal structure is complex.

The next examples show how the syntactic structures of the verb beschouwen 'consider' and the adposition buiten 'outside' are identical from this point of view. Compare the structures of buiten in (9), and beschouwen in (10). ${ }^{5}$

$$
\begin{aligned}
& {\left[{ }_{\mathrm{P} 1 \mathrm{P}}\left[{ }_{\mathrm{P}^{\circ}} \text { be-schouw -en }\left[{ }_{\mathrm{PrP}}\left[{ }_{\mathrm{Pr}^{\circ}} \text { schouw-en }\left[{ }_{\mathrm{VP}} \text { schouw }\right]\right]\right]\right]\right.} \\
& \text { BE-consider-INFL } \\
& \text { 'to consider' }
\end{aligned}
$$

In the adpositional phrase (9) and verbal phrase (10), be- is base-generated in a P1P above the PrP. In both structures, the P2 item, uit or schouw respectively, moves into the head position of be-. Note that the complex head in P1P can move further in Dutch main clauses and end up in second position, due to verb second (Den Besten 1983). However, we will not discuss this here, as the structure between $C$ and P1P is not relevant for our proposal. Comparing the structures in (9) and (10), we see that the syntactic structure and operations are completely similar in both adpositions as buiten 'outside' and verbs as beschouwen 'consider'. Note also that our analysis explains the distribution of be-: it selects a predicate phrase whose head can be any major category therefore resulting in a $b e-\mathrm{V}, b e-\mathrm{N}$ or $b e-\mathrm{A}$ combinations.

One may wonder how an adposition ends up as an adposition and how a verb ends up as a verb, if their structure is completely identical. In our analysis, all bephrases are predicates of some kind and what distinguishes between a verbal and an adpositional predicate, is the nature of the predicate that is selected by the PrP. Note that adpositional be-phrases all contain locative or directional predicates. This is not the case for $b e$-phrases that are verbs. The 'fate' of be-constructions thus

5. An interesting by-product of our analysis is that it solves one of the problems Trommelen and Zonneveld (1986) have in their morphological analysis of Dutch as a language that obeys the right-hand head rule. They observe that the head of a morphological complex word is always the right part, which seems to be contradicted by prefixes as be-, since these are the left part of the word yet do determine the category of the complex item. Our analysis is compatible with this observation. 
rests on the lexical semantics of the predicate selected by $\operatorname{PrP}$ (also see Lieber and Baayen 1993).

To sum up, we argued that the Dutch prefix be- in adpositions can be optimally analyzed as a $\mathrm{P} 1$ item that selects a predicate phrase. This analysis applies to Dutch $b e-\mathrm{V}, b e-\mathrm{N}$, and $b e-\mathrm{A}$ combinations, thus showing that predicative heads in general can combine with $b e$ - to derive new phrases. We further argued that the sequence $b e-\mathrm{V}, b e-\mathrm{N}$ or $b e-\mathrm{A}$ is derived by movement of the verb, noun or adjective in question. The selected predicate is the complement of the PrP, and moves up to be-in order to form a complex adposition or verb with be-. Note that in the introduction we mentioned that there is a difference in productivity as adpositions and $b e-\mathrm{A}$ verbal complexes are not productive whereas $b e-\mathrm{N}$ and $b e-\mathrm{V}$ verbal complexes are. We will address this in Section 4. First, in the following section, we contrast our analysis to a different analysis for verb forming be- as proposed by Hoekstra, Lansu and Westerduin (1987) in which the prefix is assumed to head a predicate phrase $\left(\operatorname{Pr}^{\circ}\right)$ within a Small Clause. We will show that this analysis runs into several problems that do not arise in our analysis.

\section{Why an analysis of be- $\operatorname{as}^{\circ}$ does not work}

In the previous section we have argued that the prefix be-can best be analyzed as a P1-type element that selects a predicate phrase as its complement. A different account for verbal complexes with be- has been offered by Hoekstra, Lansu and Westerduin (1987) (henceforth HL\&W), who argue that be- should be analyzed as the head of the predicate phrase $\left(\operatorname{Pr}^{\circ}\right)$. Section 3.1 will first briefly explain HL\&W's analysis, after which we show, in Section 3.2, that such an account runs into several problems that do not arise in our analysis.

\subsection{Hoekstra, Lansu \& Westerduin (1987): be- as $\operatorname{Pr}^{\circ}$}

HL\&W compare the behavior of be-derived verbs in Dutch to resultative verb constructions, for which a small clause analysis is assumed (cf. Bowers 1993; Den Dikken 1998, 2006). They found that these constructions have similar (resultative) meanings in some contexts like in the examples in (11).

(11) a. dat ik [SC de tuin vol] plant that I the garden full plant

b. dat ik $\left[_{S C}\right.$ de tuin be- $]$ plant that I the garden BE plant 'That I plant/cultivate the (entire) garden' 
In (11a), the verb plant semantically selects the complement denoting a mini proposition, i.e. the resultative small clause (RSC) de tuin vol 'the garden full'. HL\&W further note that while resultative small clause constructions can include a wide range of verb classes, they cannot combine with be-derived verbs. This is illustrated in (12).

(12)* dat ik de tuin vol be- plant that I the garden full $\mathrm{BE}$ plant

Because be-derived verbs and RSC have the same meaning and are in complementary distribution, HL\&W conclude that they have the same underlying structure. This means that in (11a) the verb plant selects the small clause (SC) de tuin vol 'the garden full'; whereas it selects the SC de tuin be- in (11b).

HL\&W's analysis of be-derived verbs and RSCs builds on Kayne's (1985) and related studies on particle constructions such as opeten in which the particle op heads a SC, as instantiated in (13).

(13) dat hij [sC zijn brood op] eet

that he his bread up eats

'that he finishes his sandwich'

In terms of this description, the complementary distribution between be-derived verbs and RSCs is taken to result from the fact that the prefix be-, just as the particle $o p$ in (13) and the predicate $v o l$ 'full' in (11a), represent the predicative part of the SC, though in the case of be- it cliticized to the verb on surface form. This analysis is illustrated in (14).

(14) dat ik $\left[_{S C}\right.$ de tuin be- $]$ plant

that I the garden BE plant

'that I plant/cultivate the (entire) garden'

HL\&W argue that the prefix be-and resultative elements such as $v o l$ 'full' in (11) are in complementary distribution because they involve the same structure (and express similar semantics). In other words: Because the prefixes head a SC that expresses a resultative state, they simply cannot select for another resultative predicate. According to HL\&W then, verbal be-complexes are best analyzed as small clauses headed by be-.

Comparing this analysis to our own, we observe that the two differ in that HL\&W argue that $b e$ - should be the head of the predicate phrase ( $\mathrm{Pr}^{\circ}$ or in their terms: the head of the small clause), whereas we propose that $b e$ - should be external to the small clause. It expresses $\mathrm{P} 1$, which selects a predicate phrase (arguably a small clause) as complement. These differences are not trivial as they make different predictions, which we discuss in the following section. 


\subsection{Why be-cannot be $\operatorname{Pr}^{\circ}$}

In Section 2, it was shown how Aboh's extended account explains the usage of bein adpositions and verbs. A crucial difference between this account and HL\&W's account is that HL\&W can only account for verbal $b e$ - constructions that are resultative. In their view, $b e$ - is the head of a RSC and therefore, $b e$ - must have a resultative meaning. The consequence is that those verbal occurrences of be- that are not resultative should be accounted for in another way. Under HL\&W's account, we thus end up with three types of be-; (i) a prefix explaining verbal occurrences with a resultative meaning; (ii) a prefix explaining the verbal occurrences without a resultative meaning; and (iii) a prefix found in adpositions. In HL\&W's approach, commonalities between these be- particles would be coincidental. ${ }^{6}$ In the remainder of this section, we will show that be-verbs are not necessarily, and thus not inherently, resultative and that our account can explain the complete distribution of $b e$ - in a more elegant way.

As discussed, the equivalence of sentences such as in (11) and the complementary distribution of the resultative item $v o l$ and the particle be- leads HL\&W to assume that $b e$-is resultative is as well. Consequently, it is expected that $b e$-is always in complementary distribution with a resultative item. However, the data do not support this. The examples in (15) illustrate that not all be-verbs have a resultative reading similar to the resultative meaning of beplanten 'to cultivate' in (11b). Wechsler (2005) argues that based on entailment patterns, one can test if a sentence is resultative or not. Applying this to (11) gives a correct result: When a garden is beplant, it entails that the garden is full with plants and/or trees. However, applying this test to the be-verbs in (15) gives rise to problems. Crucially, the resultative items that be- is expected to be in complementary distribution with are, to the best of our knowledge, not available for verbs as bemoederen 'to mother' and begroten 'to estimate costs'. As a result, Wechsler's entailment test fails for these verbs, since the only possible continuation for (15a)'s she mothers the child, would be, as a result, it became mothered. Clearly, this is circular.

(15) a. Dat zij $\left[_{S C}\right.$ het kind be-]moedert

that she the child BE-mothers

'That she is mothering the child'

\# she mothers the child, as a result, it became mothered.

6. One could argue these commonalities are a historical remnant. Based on the RSC account, however, one would be forced to assume that all occurrences of be- once occurred in RSCs and grammaticalized into non-resultative verbs and adpositions. 
b. Dat ik [ $\left[_{\mathrm{SC}}\right.$ de kosten be-]groot

that I de costs Be-big

'That I estimate the costs'

\# I estimate the costs, as a result, they become estimated.

Note that the examples in (15) are not exceptions; rather it seems easier to come up with $b e$-verbs that lack a resultative reading than with verbs that have a true resultative interpretation. ${ }^{7}$

In contrast, if we compare HL\&W's approach to our approach we see that the latter accounts for the commonalities and differences between the verb forming $b e$ and the adpositional forming $b e-$. in a straightforward manner. ${ }^{8}$ The similarities result from the fact that these $b e-\mathrm{X}$ combinations have the same underlying structure, while the differences are the consequences of the nature of X (i.e., V, N, A). One such difference relates to productivity: not all be-constructions are productive in Dutch. We turn to this question in the next section. ${ }^{9}$

\section{Discussion}

In this section we will focus on issues concerning the productivity and the synchronic structure of the words prefixed by be-. We will first go through the attested productivity patterns. Thereafter, we will inspect the less productive cases by using a test for compositionality as was proposed by De Belder (to appear).

The process of attaching be- to a stem varies in productivity, as has been noted in the previous section: (i) in forming verbs, $b e-\mathrm{N}$ and $b e-\mathrm{V}$ combinations are productive while $b e$-A combinations are not; and (ii) in forming adpositions, attaching $b e$ - is not productive. The productivity seems to correlate with

7. To illustrate: of the first 20 verbs formed with $b e$ - that are listed in the dictionary, only 8 have a resultative meaning: beangstigen 'to frighten', bebakenen 'to mark out', bebossen 'to aforest', beboteren 'to cover with butter', bebouwen 'to cultivate', bederven 'to spoil', bedienen 'to serve', bedijken 'to surround with dikes'. Verbs that lack a resultative meaning are the following: beademen 'to breathe air into', beamen 'to agree with', beantwoorden 'to answer', beargumenteren 'to argue', beboeten 'to fine', bebroeden 'to incubate', becritiseren 'to criticize', bedanken 'to thank', bedaren 'to calm down', bedekken 'to cover', bedenken 'to consider', and bedingen 'to insist on'.

8. The question of complementary distribution between be- and other resultative items bears also on a far more detailed analysis of PrP and the selectional requirements of P1P. We leave this for future work.

9. Another possibility is that $\operatorname{Pr}^{\circ}$ hosts the -en morpheme in Dutch as this is an inflectional element. Recall that Aboh (2010) assumes that small clauses are defective clauses which includes IP and CP - see footnote 2 . 
the compositionality of the meaning of the complex element: when the formation is not productive, there is no systematic and clear meaning of be-. Thus, when forming a $b e$-verb with a noun as its base, the meaning of the complex element is compositionally derived from both parts: bebossen 'to form a forest' in (16a) has both the meaning of 'forest' and ' $b e-$ ', in which the latter conveys the meaning 'to cover something completely with $\mathrm{x}$ '. The same holds for $b e-\mathrm{V}$ constructions, such as bekijken 'to look at' in (16b). This verb differs from kijken 'to look' in the sense that bekijken has more focus on the object. In contrast, in most be-verbs with an adjective as its base, the meaning of the adjective is not visible anymore in the complex word, as for instance in begroten 'to estimate costs' in (16c). The same holds when be-forms an adposition, as in (16d).

$\begin{array}{lll}\text { (16) a. } & \text { bos } & \text { be-bos } \\ \text { 'forest' } & \text { 'to afforest' } \\ \text { b. } & \text { kijk } & \text { be-kijk } \\ & \text { to look' } & \text { 'to look at' } \\ \text { c. } & \text { groot } & \text { be-groot } \\ & \text { 'big' } & \text { 'to estimate costs' } \\ \text { d. } & \text { over } & \text { b(e)-oven } \\ & \text { 'over' } & \text { 'upstairs' }\end{array}$

The examples in (16) show the difference in compositionality: some be-X combinations seem to have lexicalized while others have not. This is also what Lieber and Baayen (1993) found, who did a corpus study and listed be-verbs that did not occur in existing and extensive lists of be-verbs (provided in Schultink 1962, De Vries 1975) and that therefore 'share an intuitive flavor of newness' (Lieber and Baayen 1993:73). Lieber and Baayen show that there are only 8 occurrences of be-A verbs, whereas new be- $\mathrm{N}$ verbs occur 50 times and be-V verbs 34 times.

In order to evaluate the degree of lexicalization, we will use De Belder's (to appear) test for compositionality. She uses a compounding test to show the difference between morphologically complex and morphologically simplex words. De Belder notices that verbs formed with the prefix ver- in Dutch can behave in different ways, as illustrated in the examples in (17) (to appear: 13-14). First, when a ver- $\mathrm{V}$ combination has a compositional meaning (i.e. when the verbs are derived by means of a productive word-formation process), the word is morphologically complex and ver-behaves like a derivational affix. An example is provided in (17a), in which ver- refers to an increasing degree. Second, when the meaning of $v e r-\mathrm{V}$ is opaque (i.e. the meaning of the complex item is not determined by the meanings of its parts) as in (17b), the word is simplex. In these unproductive cases, De Belder argues that ver-does not have the status of a prefix, but rather is part of the root. 
(17)
Base
Verb
a. Vlaams
ver-vlaams-en
Flemish
VER-flemish-INFL
'Flemish'
'to become more Flemish'
b. wen
ver-wen-en
get.used.to
VER-get.used.to-INFL
'to get used to'
'to spoil'

To test the different types of ver-X combinations, De Belder looks at root primary compounds. This type of compound consists of two parts that are non-categorized elements, so-called roots. For the details of her analysis, we refer the reader to De Belder (to appear). Importantly for us, her claim is that in these compounds, derivational affixes cannot occur in the first part of a compound, as is shown in (18a). This explains the different ways in which ver- behaves: Exactly those verwords that have a compositional meaning, cannot occur as the left hand part of a compound, illustrated in (18b). In contrast, the ver-words that are more opaque can occur as the left hand part of a compound, as in (18c). From this De Belder concludes that in the latter cases, ver- is not an affix, and the word is thus simplex - unlike its productive counterpart.
a. * spaar-zaam-attitude save-ZAAM-attitude
b. ${ }^{\star}$ ver-slaap-tijd ver-sleep-time
c. verdwijn-truc disappear-act 'disappearing act'

If we now apply this test to be-, we see similar behavior as with ver-. In case of the adpositions formed with $b e$-, the adposition clearly may occur as the left part of a compound, as is illustrated in (19).

(19) a. boven-verdieping upstairs-floor 'higher floor'

b. binnenhuis-architect inside.house-architect 'interior designer'

c. buiten-zwembad outside-swimmingpool 'outside swimmingpool' 
However, in the case of verbs formed with be-, the judgments become less clear. First, if be-attaches to a category-less root, it is certainly possible to have it as the left part of a compound, as in (20a). In contrast, when be- attaches to nouns or verbs, the result is ungrammatical $(20 b, c)$. Finally, although words formed with adjectives do not have a compositional meaning, it is hard to find a grammatical compound with be-A (20d), contrary to De Belder's predictions.

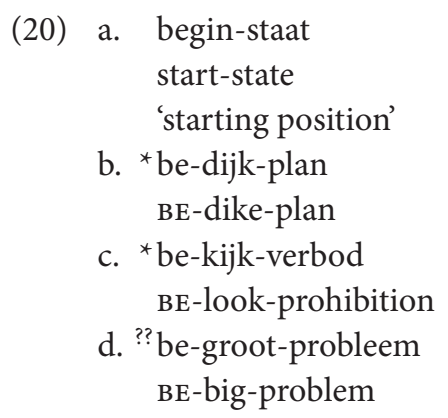

This leads us to conclude that in the case of adpositions and verbs with a root as its base, the structure in (6) is most likely not present anymore in the synchronic grammar. However, we would like to propose that this structure can be indicative of the grammaticalization path of the prefix, in terms of Roberts and Roussou (2003) and the subsequent lexicalization of the be-phrase. Moreover, if be- has grammaticalized in an adpostion as boven, it is not surprising that the schwa in the prefix has disappeared. In the case of the verb-forming prefix, the status of the structure is less clear. Probably the proposed structure is still present if be-attaches to verbs and nouns, since the meaning can be easily derived and it is not possible to form a compound. Moreover, we can easily come up with non-existing, yet possible be-N combinations, as was also shown by Lieber and Baayen (1993). The example in (21) illustrates this once more.

(21) be-deur-en

BE-door-INFL

'to provide something with doors'

Finally, the status of $b e-\mathrm{A}$ is unclear. As mentioned above, the formation of verbs with $b e$ - and an adjective as its base seems to be not productive, but the root-compounding test as proposed by De Belder is not conclusive for this complex. When be-A occurs as the left part of the compound, the result is ungrammatical, but the meaning of be-A is certainly not (completely) compositional. Therefore, we think that this word-complex is on its way to becoming fully lexicalized. However, it remains an open issue what exactly the relation is between our proposed structure and issues of grammaticalization and compositionality. 


\section{Conclusion}

In this paper we have presented a uniform analysis of the Dutch prefix be-, which forms both verbs and adpositions. We extended Aboh's (2010) analysis of adpositions formed with $b e$ - to verbs formed with be-. We argued that there is one prefix that spells out a functional category, embedding a predicate phrase. This captures the fact that be-can attach to all parts of speech and forms both adpositions and verbs. Finally, we provided arguments against Hoekstra, Lansu and Westerduin's (1987) small clause account of be-, showing that be-cannot be the head of a predicate phrase $\left(\mathrm{Pr}^{\circ}\right)$, but is best analyzed as a functional category $\left(\mathrm{P} 1^{\circ}\right)$ that embeds a predicate phrase.

\section{Acknowledgements}

First, we would like to thank Enoch O. Aboh for all helpful discussions and advice. Second, we thank the audience at the TIN-dag 2015 for their fruitful comments - we are especially grateful to Marijke De Belder and Hans Broekhuis. Finally, we would like to thank Jan Don, Fenna Bergsma and two anonymous reviewers for useful feedback on earlier versions of this paper.

\section{References}

Aboh, Enoch O. 2010. “The P-route”. Mapping spatial PPs ed. by Guglielmo Cinque, 225-260. New York: Oxford University Press. DOI: 10.1093/acprof:oso/9780195393675.003.0007

Baker, Mark. 1988. Incorporation: A Theory of Grammatical Function Changing. University of Chicago Press, Chicago.

Booij, Geert. 2002. The morphology of Dutch. Oxford: Oxford University Press.

Bowers, J. 1993. “The syntax of predication”. Linguistic Inquiry 24.591-656.

De Belder, M. To appear. "The root and nothing but the root: primary compounds in Dutch". Syntax.

De Haas, Wim \& Mieke Trommelen. 1993. Morfologisch handboek van het Nederlands: Een overzicht van de woordvorming. 's-Gravenhage: SDU Uitgeverij.

De Vries, Jan Willem. 1975. Lexicale Morfologie van het Werkwoord in Modern Nederlands. Leiden: Universitaire Pers.

Den Besten, Hans. 1983. "On the interaction of root transformations and lexical deletive rules". On the formal syntax of the Westgermania: Papers from the third Groningen Grammar Talks ed. by Werner Abraham. Linguistik Aktuell 3:47-131 Amsterdam/Philadephia: John Benjamins. DOI: 10.1075/la.3.03bes

Den Dikken, Marcel. 1998. "Predicate inversion in DP". Possessors, predicates and movement in the determiner phrase ed. by A. Alexiadou and C. Vilder, 177-215. Amsterdam: John Benjamins Publishing. DOI: 10.1075/la.22.08dik 
Den Dikken, Marcel. 2006. Relators and linkers: The syntax of predication, predicate inversion, and copulas. Cambridge, Mass.: MIT Press.

Hoekstra, T.A., M. Lansu \& M. Westerduin. 1987. “Complexe Verba”. Glot 10.61-77.

Holmberg, Anders. 2002. "Prepositions and PPs in Zina Kotoko" Some Aspects of the Grammar of Zina Kotoko ed. by B. Kappel Schmidt, D. Odden and A. Holmberg, 162-174. Muenchen: Lincom Europa.

Kayne, R. 1985. "Principles of particle constructions". Grammatical representation 22.101-140.

Lieber, Rochelle \& Harald Baayen. 1993. "Verbal prefixes in Dutch: a study in lexical conceptual structure". Yearbook of Morphology 1993 ed. by G. Booij and J. van Marle, 51-78. Dordrecht: Springer. DOI: 10.1007/978-94-017-3712-8_3

Roberts, Ian G. \& Anna Roussou. 2003. Syntactic change: A minimalist approach to grammaticalization. Cambridge: Cambridge University Press. DOI: 10.1017/CBO9780511486326

Schultink, Henk. 1962 [1980]. De morfologische valentine van het ongelede adjectief in modern Nederlands. Utrecht: Hes Publishers.

Talmy, Leonard. 2000. Toward a cognitive semantics: Volume I. Cambridge, Mass.: MIT Press.

Trommelen, M. \& W. Zonneveld. 1986. "Dutch Morphology: Evidence for the Righthand Head Rule”. Linguistic Inquiry 17.147-170.

Wechsler, Stephen. 2005. "Resultatives under the 'Event -Argument Homomorphism' model of telicity". The Syntax of Aspect: Deriving Thematic and Aspectual Interpretation ed. by N. Erteschik-Shir and T. Rapoport, 255-273. Oxford: Oxford University Press.

\section{Authors' addresses}

Paula Fenger

University of Connecticut

Department of Linguistics

365 Fairfield Way, Oak Hall (East SSHB),

Unit 1145

Storrs, CT, 06269-1145

USA

paula.fenger@uconn.edu

Ava Creemers

University of Pennsylvania

Department of Linguistics

619 Williams Hall

255 S 36th Street

Philadelphia, PA, 19104-6305

USA

creemers@sas.upenn.edu
Marlijn Meijer

Humboldt-Universität zu Berlin

Institut für Anglistik und Amerikanistik

Unter den Linden 6, D-10099 Berlin

Germany

meijeram@hu-berlin.de 